\title{
Functionalization of Si-C Using TEOS (Tetra Ethyl Ortho Silica) as Precursor and Organic Catalyst
}

\author{
Riani Ayu Lestari ${ }^{1,2}$, Muthia Elma $^{1,2^{*}}$, Erdina Lulu Atika Rampun ${ }^{1,2}$, Anna Sumardi ${ }^{1,2}$, Adhe Paramitha ${ }^{1,2}$, Aptar Eka \\ Lestari $^{1}$, Sadidan Rabiah ${ }^{1,2}$, Zaini Lambri Assyaifi ${ }^{1,2}$, and Gesit Satriaji ${ }^{1,2}$ \\ ${ }^{1}$ Department of Chemical Engineering, University of Lambung Mangkurat, Banjarbaru. South Kalimantan. Indonesia \\ ${ }^{2}$ Materials and Membranes Research Group ( $\left.\mathrm{M}^{2} \mathrm{ReG}\right)$, University of Lambung Mangkurat, Banjarbaru, South Kalimantan, Indonesia
}

\begin{abstract}
Silica network was tailored configuring siloxane (Si-O-Si) and silanol (Si-OH) groups which are essential to produce porous-structured materials. As silanols are hydrophilic, react with water to form fouling. This research address to actualize strategy for synthesizing highly functionalized silica carbon (SiC) using hybrid organic-inorganic structures as the primary method for improving hydro-stability by employing precursor TEOS and organic catalyst through a sol-gel process. Catalysis employs citric acid or citric acid-ammonia whereas carbon templated into silica network. The synthesis scheme involves: a) solgel process at $0^{\circ} \mathrm{C}$ and b) calcination. Silica sol dried into xerogels were prepared and calcined at $200^{\circ} \mathrm{C}$ and $250^{\circ} \mathrm{C}$. Characterization of xerogels showed the infrared band areas of the organic groups to evaluate the thermal stability. For xerogel employed single $(\mathrm{pH} 5.5)$ and dual $(\mathrm{pH} 7.65)$ catalyst, infrared spectra showed mostly look similar Si-C area at similar wavelength. Silica xerogel is more effectively prepared from TEOS with one-step single acid catalyst including calcination.
\end{abstract}

\section{Introduction}

Silica as inorganic material has best properties such as high chemical, thermal and mechanical stabilities [1]. The functionalization of silica material is important to know the mesoporous silica material applicable to desalination. TEOS (tetra ethyl ortho silicate) as hydrophobic inorganic material from metal alkoxide (precursor) is a skillfully utilized and easy controlled structure for membrane synthetic under the sol-gel process [2]. However, the limitation of using silica is low hydro-stability.

In order to increase hydro-stability and robustness of silica matrices against both physical and chemical resistances, many strategies of pure silica modification can be executed such as templated carbon silica, hybrid organic-inorganic silica structure [3], cobalt [4, 5], nickel [6-8], and iron [9]. Templated carbon modification was investigated in using Pluronics triblock copolymers [10] and surfactants for desalination application [11, 12]. For other method, hybrid organic-inorganic silica structure was investigated that silica-pectin as carbon templates promised excellent membrane due to its excellent performance indicated by 5 times water flux higher than using templeting carbon sourced from P123 triblock copolymer. Therefore, pectin as natural source of carbon and easy obtained from fruit peel or industries waste can reduce one step process of templating and high production cost [13].

To reach efficiency cost in material and process, the importance of organic was utilized for catalyst as well as carbon source to form the silica network. Carbon addition from organic catalyst create robustness and change the structure of silica matrix $[14,15]$. It is new potential strategy to solve the main problem in hydrostability by configuring Si-C on silica network. As reported by Elma and Setyawan [16] that success to obtain Si-O-C in silica network by employing citric acid as organic catalyst and carbon source [17]. But in this study the lower calcination temperatures are applied and compare the functionalization between acid catalyts and dual base acid catalyst. This research aims to synthesizing highly functionalized silica carbon (Si-C) using hybrid organicinorganic structures by employing precursor TEOS and organic catalyst through a sol-gel process. The functionalization using infrared spectra at $1400-700 \mathrm{~cm}^{-1}$ of wavelength.

\footnotetext{
Corresponding author: m.elma@ulm.ac.id
} 


\section{Experimental}

\subsection{Variable and Materials}

Silica sols was synthesized by using tetra ethyl ortho silicate (TEOS: Sigma-Aldrich), ethanol (EtOH: 70\%) and water as solvent, also dilute citric acid (23.4\%, Merck) and ammonia ( $\mathrm{NH}_{3}$, Merck). Table 1 summarize each composition in molar ratio unit of materials to prepare two types of membrane.

FTIR analysis was delivered to understanding effect of experimental variables. Experiment was run as function of two types of catalyst (single citric acid catalyst and dual citric acid-base catalyst) and 3 thermal treatment condition (uncalcination; $200^{\circ} \mathrm{C}$ calcination and $250^{\circ} \mathrm{C}$ calcination).

\subsection{Procedures}

To reach characterization step for analyzing organic group in silica sol, there are many initial step to be executed. Pretreatment was followed by some material for preparation such as, precursor TEOS, ethanol solution, and acid or base catalyst. Sol-gel reaction consist of hydrolysis and condensation reaction. Sol-gel reaction was reacted precursor TEOS, ethanol, water, and catalyst to produced silica sol. For characterization silica sol should be transform into xerogel (dried sol) and grounded into powder to be applied as FTIR sample. Briefly, procedure of experiment can be showed in Fig. 1, and solgel process can be run in equipment installation in Fig 2 .

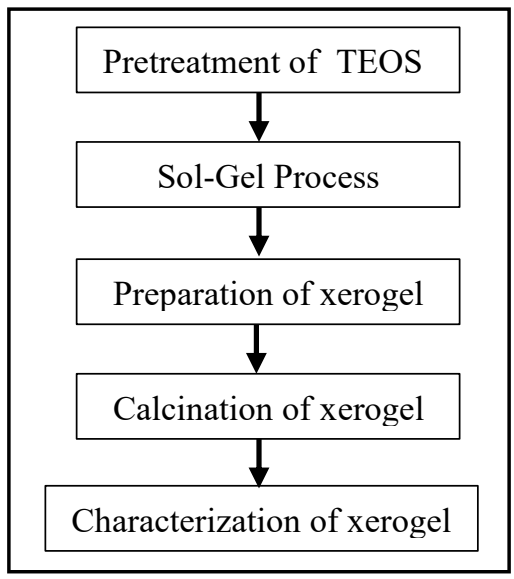

Fig. 1. Flow Diagram of Experiment

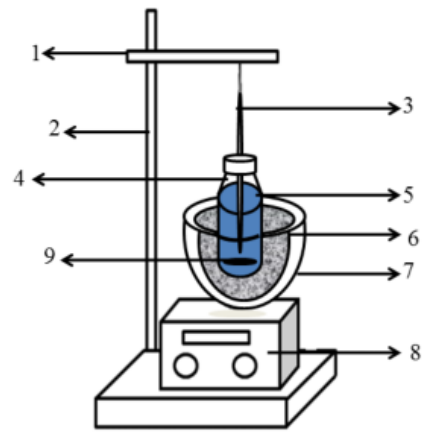

1. Clamp

2. Stand

3. Thermometer

4. Reagent bottle

5. Solution

6. Ice

7. Container

8. Magnetic Stirrer

9. Stirrer

Fig. 2. Sol-Gel Process

Table 1. Silica sols molar ratio.

\begin{tabular}{|c|c|c|c|c|c|c|}
\hline $\begin{array}{c}\text { Types of } \\
\text { membranes }\end{array}$ & $\begin{array}{c}\text { Types of } \\
\text { catalyst }\end{array}$ & TEOS & $\mathbf{E t O H}\left[\mathbf{x 1 0}{ }^{1}\right]$ & $\mathbf{C}_{6} \mathbf{H}_{8} \mathbf{O}_{7}\left[\mathbf{x 1 0}^{-4}\right]$ & $\mathbf{N H}_{3}\left[\mathbf{x 1 0} \mathbf{0}^{-3}\right]$ & $\mathbf{H}_{2} \mathbf{O}$ \\
\hline A & $\begin{array}{c}\text { Single acid } \\
\text { catalyst } \\
(\mathrm{pH}=5.5)\end{array}$ & 1 & 3.8 & 7 & - & 5 \\
\hline B & $\begin{array}{c}\text { Dual acid-base } \\
\text { catalyst } \\
(\mathrm{pH}=7.6)\end{array}$ & 1 & 3.8 & 7 & 3 & 5 \\
\hline
\end{tabular}

\subsubsection{One-step sol gel process}

This process employed citric acid as organic catalyst. Firstly, EtOH was added into reagent bottle followed by cooling process at $0^{\circ} \mathrm{C}$ and stirring at $250 \mathrm{rpm}$ for 5 minutes. Then TEOS was dropped and resting. After resting for 5 minutes TEOS and EtOH mixture was dropped wise by $\mathrm{C}_{6} \mathrm{H}_{8} \mathrm{O}_{7}$ to produce sol through one-step sol gel process.

\subsubsection{Two-step sol gel process}

According one-step sol gel process, this difference of procedure put on addition of base catalyst. Et-OH, TEOS and citric acid was mixed at $0^{\circ} \mathrm{C}$ for an hour. Then, followed by addition of $\mathrm{NH}_{3}$ and refluxed for 2 hours at $0^{\circ} \mathrm{C}$ and $250 \mathrm{rpm}$ stirring.

\subsubsection{Calcination}

Silica sol was dried in oven at temperature controlled $60^{\circ} \mathrm{C}$ for 24 hours to obtain dried gel. Dried gel (xerogels) was subsequently grounded into fully homogeny powder and calcined in temperature controlled at varying temperature $200^{\circ} \mathrm{C}$ and $250^{\circ} \mathrm{C}$ for $1 \mathrm{~h}$. Xerogels were characterized using FTIR at wavelength range 4000-600 $1 / \mathrm{cm}$. 


\subsection{Characterization Using FTIR}

As one of indirect analysis methods, Fourier Transform Infrared (FTIR) provides information of functional group within the silica network $[18,19]$. According to presence hypothesis of silanol, siloxane and $\mathrm{Si}-\mathrm{C}$ bonds in matrix, Infrared spectra was carried out along with $1400-600 \mathrm{~cm}^{-1}$ wavelength. Some organic groups and silicone compound were summarized in Table 2.

Peak deconvulation wavelength for $1400-600 \mathrm{~cm}^{-1}$ was showed by FityK software based on Gaussian line shapes at least square and normalized peak against baselines[20] to understand proportional group in compound.

Table 2. Group frequencies for organic and silicone-oxy compound[21]

\begin{tabular}{|c|c|}
\hline $\begin{array}{c}\text { Wave number } \\
(\mathbf{1} / \mathbf{c m})\end{array}$ & Organic group \\
\hline 1650 & $\mathrm{C}=\mathrm{C}$ stretch \\
\hline 1460 & $\mathrm{C}-\mathrm{H}$ methyl scissor \\
\hline 1375 & $\mathrm{C}-\mathrm{H}$ \\
\hline 1260 & $\mathrm{Si}-\mathrm{C}$ \\
\hline $1000-1100$ & $\mathrm{Si}-\mathrm{O}-\mathrm{Si}$ \\
\hline 990 & $\mathrm{C}=\mathrm{C}-\mathrm{H}$ bend \\
\hline 940 & $\mathrm{Si}-\mathrm{OH}$ \\
\hline$<800$ & $\mathrm{Si}-\mathrm{C}$ \\
\hline
\end{tabular}

\section{Result and Discussion}

\subsection{Silica carbon xerogels characterization}

Xerogels were characterized to analyze functional group of siloxane (Si-O-Si), silanol $(\mathrm{Si}-\mathrm{OH})$ and silica carbon (Si-C) on the silica samples. Fourier Transform Infra-Red (FTIR) showed in Fig 3 was performed to analyze the functional group of silica xerogel and set as a function of catalyst type and calcination temperature. Forasmuch as the aim of preparing this xerogel is to be used as thin film membrane coating, in order that it is so important to comprehend if there are 3 groups.

The spectra is at around $1060 \mathrm{~cm}^{-1}, 942 \mathrm{~cm}^{-1}$ and 800 $\mathrm{cm}^{-1}$ to siloxane, silanol, and silica-carbon groups, respectively [22]. The wavelength of $\sim 1060 \mathrm{~cm}^{-1}$ is called asymetric strecthing vibration. Refer to Fig 3 employing single acid catalyst at $200^{\circ} \mathrm{C}$ calcined, $250^{\circ} \mathrm{C}$ calcined and uncalcined there were 3 peaks indicating presence of siloxane ( $\mathrm{Si}-\mathrm{O}-\mathrm{Si})$, silanol $(\mathrm{Si}-\mathrm{OH})$, and silica-carbon ( $\mathrm{Si}-$ C) at wave number around $1060 \mathrm{~cm}^{-1}, 940 \mathrm{~cm}^{-1}, 780 \mathrm{~cm}^{-1}$, respectively. As well as by employing only acid catalyst, by employing dual acid-base catalyst also were 3 peaks of compound at around $1062 \mathrm{~cm}^{-1}, 959 \mathrm{~cm}^{-1}, 790 \mathrm{~cm}^{-1}$. This result show that xerogel peaks for single acid catalyst and dual acid-base catalyst using citric acid were similar. Higher calcination temperature also makes carbon dissapear due to decomposition, while silanol and siloxane are remain.

Increasing rate of sol-gel process by employing acid or base catalyst indirectly effected in formation of bonding, robustness and pore size of silica network. Silanol $(\mathrm{Si}-\mathrm{OH})$ is hydrophilic and damaged highly on silica network. Therefore, presence of organic compound sourced from organic catalyst effected to form silicacarbon (Si-C) bonds. Hybrid silica using precursor TEOS and organic catalyst for improving high hydro-stability and separating performance are critically reported by Elma (2012) [3].

\subsection{Peak area ratio of carbon xerogels}

Calcination as burning process is reaction decomposition to degrade carbonate gas or hydroxide content. Thus, powder after calcination has been in high purity. Calcination is run in high temperature depending on material properties.

$\mathrm{Si}-\mathrm{C}$ formation and presence effected in both sol-gel reaction and calcination process, respectively. At high calcination temperature silica-carbon content carried out because of damaging. Consequently, due to network has leaving empty space, changing network structure and enlarging of pore size, robustness gradually decrease. Elma, et al (2019) reported that low calcination temperature are convenient for presence of silica-carbon in membrane network [22].

As addition analysis was carried out an overlapping of peak deconvolution to determine surface area of functionalize group compound in organosilica xerogels by Fityk software program as shown on Fig. 4. Employe of citric acid and based catalyst into organosilica sols were rendering to form silanol ( $\mathrm{Si}-\mathrm{O})$ and siloxane ( $\mathrm{Si}-\mathrm{O}-$ $\mathrm{Si})$ groups via hydrolysis and condensation reaction. According to fitting result as display on Fig.4 (dotted calcined $250{ }^{\circ} \mathrm{C}$ ), deconvolution of surface area ratio of silanol:siloxane of single organo catalyst is showing better than dual organo catalyst of 0.1 a.u. is a bit than 0.5 a.u.. It means functionalize of siloxane group is dominate in organosilica xerogel which the significance of producing the organosilica structure become mesopore [23]. Comparing to previous study reported [24] by of relative ratio of $\mathrm{Si}-\mathrm{OH} / \mathrm{Si}-\mathrm{O}-\mathrm{Si}$ surface area in this work is quiet small $50 \%$ at same calcine temperature $250{ }^{\circ} \mathrm{C}$. It is indicate both of result have similar structure.

The effect of calcination was investigated by deconvolution at a wavelength of $940 / 1080 \mathrm{~cm}^{-1}$ (Si$\mathrm{OH} / \mathrm{Si}-\mathrm{O}-\mathrm{Si}$ ) on Figure 4 . It should be emphasized that silanol formation in the calcined xerogels (employs both single acid catalyst and dual acid-base catalyst) was reduced at $250^{\circ} \mathrm{C}$. This means that once the calcination temperature increases the silanol concentration decreases. Rising of calcined temperature lead the minimize oH peak. In other hand, aalcination at $250{ }^{\circ} \mathrm{C}$ offers higher carbon content showed at wavelength of $800 \mathrm{~cm}^{-1}$ (Si-C), which carbon in silica matrices may reduce the hydrophilic properties of silica network.

Deconvulation for Figure 4(d) showed that employing citric acid was leaded to decreasing of silanol/siloxane ratio as a function enhancing on calcination temperature. Equivalently, Figure $4 \mathrm{~d}$ shows two interesting peak that is siloxane and silica carbon. Therefore, condensation process particularly produce high siloxane. Also, 
nucleophilic performance increases and partially substituted to form silica-carbon configuration in silica network.

Meanwhile, in Figure 4(c) the higher calcination temperature makes the lower silica-carbon effected in employing base catalyst to high siloxane formation. Increasing of catalyst concentration cannot effect steric factor for carbon substitution.

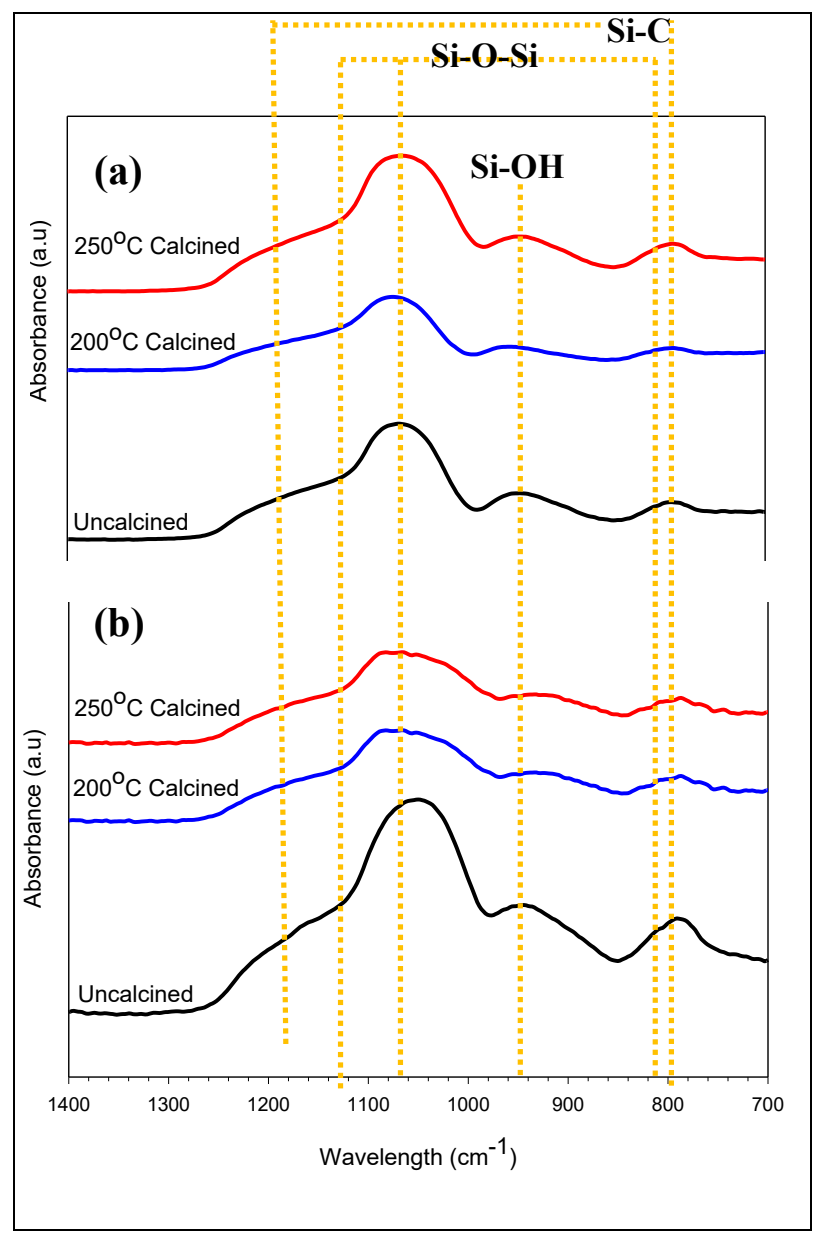

Fig. 3 FTIR spectra of the silica xerogels employed (a) dual citric acid-ammonia catalyst and (b) single citric acid catalyst.

Table 3. Peak area using Fityk (curve-fitting) software

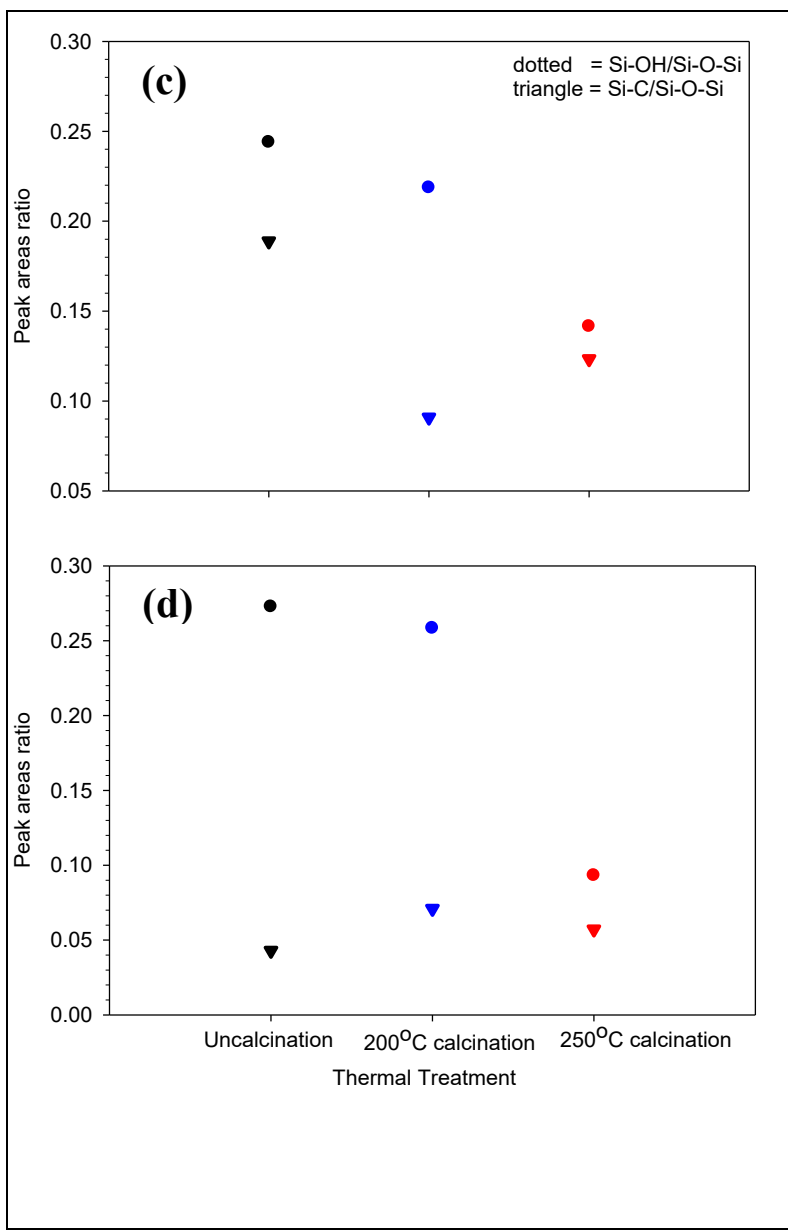

Fig. 4. The peak area ratio at $200 \mathrm{oC}$ calcined, $250 \mathrm{oC}$ calcined and uncalcined of silica carbon peak against siloxane peak (c) by employing dual citric-acid-ammonia catalyst at 790 $\mathrm{cm}^{-1} / 1062 \mathrm{~cm}^{-1}$ and silanol peak against siloxane peak at $959 \mathrm{~cm}^{-}$ $1 / 1062 \mathrm{~cm}^{-1}$ and (d) by employing single citric acid catalyst at $780 \mathrm{~cm}^{-1} / 1060 \mathrm{~cm}^{-1}$ and silanol peak against siloxane peak at 940 $\mathrm{cm}^{-1} / 1060 \mathrm{~cm}^{-1}$; as function of thermal treatment

\begin{tabular}{|l|c|c|c|c|c|c|c|c|}
\hline \multirow{3}{*}{$\begin{array}{c}\text { Xerogel thermal } \\
\text { treatment }\end{array}$} & \multicolumn{9}{|c|}{ Area $\left.\mathbf{( c m}^{2}\right)$} \\
\cline { 2 - 9 } & \multicolumn{2}{|c|}{ Si-OH } & \multicolumn{2}{c|}{ Si-O-Si } & \multicolumn{2}{c|}{ Si-OH/Si-O-Si } & \multicolumn{2}{c|}{ Si-C (800) } \\
\cline { 2 - 9 } & Single & Dual & Single & Dual & Single & Dual & Single & Dual \\
\hline Uncalcination & 1.59 & 1.87 & 5.83 & 7.69 & 0.27 & 0.24 & 0.25 & 1.45 \\
\hline $200^{\circ} \mathrm{C}$ calcination & 1.22 & 2.54 & 4.70 & 11.64 & 0.26 & 0.22 & 0.33 & 1.06 \\
\hline $250^{\circ} \mathrm{C}$ calcination & 0.67 & 1.84 & 7.17 & 13.03 & 0.09 & 0.14 & 0.41 & 1.61 \\
\hline
\end{tabular}

\section{Conclusion}

Silica sol xerogels were successfully fabricated using single acid catalyst (citric acid) and dual acid base catalyst (citric acid and ammonia) under low calcination process $\left(200\right.$ and $250^{\circ} \mathrm{C}$ ). Higher temperature makes carbon groups loss, while siloxanes and silanols are still remain. Based on FTIR, single acid catalyst using organic catalyst shows more efficient to produce mesoporous structure. It will minimize the use of base catalyst. Organic catalyst also enhancing hydrostability and robustness of silica network.

The authors gratefully thank the facilities of Process Technology Laboratory, Engineering Faculty, University of Lambung Mangkurat. Riani Ayu Lestari thanks to KURITAAIT Research Grant 2018. Muthia Elma thanks to (i) Alumni 
Grants Scheme Batch 2 in 2018-2019, (ii) Applied Research Universities Grant 2019-2020, (iii) Thesis Magister Grant 2019 and (iv) Post-Doctoral Grant 2017-2018, Directorate of Research and Community Service, the Ministry of Research, Technology and Higher Education Republic of Indonesia.

\section{References}

1. S. Benfer, U.P., H. Siewert, G. Tomandl Development and characterization of ceramic nanofiltration membranes. Sep. Purif. Technol, 2001. 22-23: p. 231-237.

2. H. Yan, W.Y., Y.Hongxing, TEOS/silane coupling agent composed double layers structure: A novel super-hydrophilic coating with controllable water contact angle value. Applied Energy, 2015.

3. M.Elma, C.Y., D.K.Wang, S.Smart, J.C. Diniz da Costa, Microporous Silica Based Membrane for Desalination. Journal of Water, 2012.

4. Smart, S., J.F. Vente, and J.C. Diniz da Costa, High temperature $\mathrm{H} 2 / \mathrm{CO} 2$ separation using cobalt oxide silica membranes. International Journal of Hydrogen Energy, 2012. 37(17): p. 12700-12707.

5. Liu, L., et al., Interlayer-free microporous cobalt oxide silica membranes via silica seeding sol-gel technique. Journal of Membrane Science, 2015. 492: p. 1-8

6. Kanezashi, M. and M. Asaeda, Hydrogen permeation characteristics and stability of $\mathrm{Ni}$ doped silica membranes in steam at high temperature. Journal of Membrane Science, 2006. 271(1): p. 86-93.

7. Darmawan, A., et al., Interlayer free-nickel doped silica membranes for desalination. IOP Conference Series: Materials Science and Engineering, 2017. 172(1): p. 012001.

8. Darmawan, A., et al., Structural evolution of nickel oxide silica sol-gel for the preparation of interlayer-free membranes. Journal of NonCrystalline Solids, 2016. 447: p. 9-15.

9. Darmawan, A., et al., Binary iron cobalt oxide silica membrane for gas separation. Journal of Membrane Science, 2015. 474: p. 32-38.

10. Ladewig, B.P., et al., Preparation, Characterization and Performance of Templated Silica Membranes in Non-Osmotic Desalination. Materials, 2011. 4(5): p. 845.

11. Duke, M.C., S. Mee, and J.C.D. da Costa, Performance of porous inorganic membranes in non-osmotic desalination. Water Research, 2007. 41(17): p. 3998-4004.

12. Wijaya, S., M.C. Duke, and J.C. Diniz da Costa, Carbonised template silica membranes for desalination. Desalination, 2009. 236(1): p. 291298.

13. Syauqiyah, I., et al. Interlayer-free Silica-carbon Template Membranes from Pectin and P123 for Water Desalination MATEC Web of Conferences 2019 [cited 280; 3017 ]. Available from: https://doi.org/10.1051/matecconf /201928003017.
14. M.C. Duke, J.C.D.d.C., D.D. Do, P.G. Gray, G.Q. $\mathrm{Lu}$, Hydrothermally robust molecular sieve silica for wet gas separation. Adv. Funct. Mater, 2006. 16: p. 1215-1220.

15. M. Elma, D.K.W., C. Yacou, J. Motuzas, J.C. Diniz da Costa, High Performance interlayer-free mesoporous cobalt oxide silica membranes for desalination application. Journal of Desalination. Journal of Desalination, 2015b. 365: p. 308-315.

16. Elma, M. and H. Setyawan, Synthesis of Silica Xerogels Obtained in Organic Catalyst via Sol Gel Route. IOP Conference Series: Earth and Environmental Science, 2018. 175(1): p. 012008.

17. M. Elma, H.S., Synthesis of Silica Xerogels Obtained in Organic Catalyst via Sol Gel Route. IOP Conference Series : Earth and Environmental Science, 2018.

18. M. Elma, D.K.W., C. Yacou, J.C.Diniz da Costa, Interlayer-free P123 carbonised templete silica membranes for desalination with educed salt concentration polarisation. J. Membr. Sci, 2015a. 475: p. 376-383.

19. Y. T. Chua, C.X.C.L., F. Kleitz, and S. Smart, Sythesis of mesoporous carbon-silica nanocomposite water-treatment membranes using a triconstituent co-assembly method. J. Mater. Chem. A., 2015. 00: p. 1-3.

20. Wojdyr, M., FityK: A genral-purpose peak fitting program. J. Appl. Crystallogr, 2010. 43: p. 11261128.

21. Socrates, G., Infrared and Raman Characteristics Group Frequencies: Tables and Charts. 3rd ed. 2001, West Sussex: John Wiley \& Sons Ltd.

22. M.Elma, R.A., Erdina, Syarifah, Dewi.S,Norlian, Dhimas, Fabication of interlayer-free silica-based membranes-effect of low calcination temperature using an organo-catalyst. Membrane Technology, 2019: p. 6-10.

23. Pratiwi, A.E., et al., Innovation of Carbon from Pectin Templated in Fabrication of Interlayer-free Silica-Pectin Membrane. Jurnal Kimia Sains dan Aplikasi, 2019. 22(3): p. 93-98.

24. Elma, M., et al., Fabrication of interlayer-free silica-based membranes - effect of low calcination temperature using an organo-catalyst. Membrane Technology, 2019. 2019(2): p. 6-10. 